\title{
Linguistic liminality in the early years of school: Urban South African children 'betwixt and between'" languages of learning
}

\begin{abstract}
This article is about an investigation into the English spoken language competence of 144 first graders in two urban ('township') schools in the Gauteng Province of South Africa. The study was conducted from an anthropological and a cognitive developmental perspective. In one school isizulu and Sesotho are used mainly as medium of instruction, while in the other school the language of teaching and learning is English. The inquiry is part of longitudinal panel research in which children's overall development and school progress over four years is documented by way of growth modelling. This initial assessment of the children's basic interpersonal communication skills in English found, not unexpectedly, that the children in the first mentioned school know English mostly to the extent of the naming of objects, while the children in the other school are able to use morpho-syntactically more complex language. These findings may shed some light on the phenomenon of school culture liminality in its interplay with linguistic liminality, considering that children's basic English may scaffold their academic English.
\end{abstract}

Keywords: cognitive academic language; linguistic liminality; medium of instruction; school culture; rite of passage; early-exit model.

Elizabeth Henning, Centre for Education Practice Research, University of Johannesburg. E-mail: ehenning@uj.ac.za. Graham Dampier, Department of Childhood Education, University of Johannesburg. E-mail: gadampier@uj.ac.za. 


\section{Introduction: Moving from home to school and into the 'mother tongue' debate}

In this article we investigate one aspect of the issue of language of learning and teaching (LoLT) in the early grades in South African schools, namely linguistic liminality, a term which refers to a transition phase, such as the initial phase of getting to know the discursive practices of school learning. Recent publications on issues of language of instruction, in this country, highlight the on-going conundrum of what could be reasonably considered as the optimal language for learning in early school education (Makalela, 2009; 2005; Mashiya, 2011; Heugh, 2006; 2008; Koch et al., 2009; Burkett \& Landon, 2004; Alexander, 2009). In this article we enter that debate with regard to how it concerns children who move from home to school within their 'mother community' only marginally. In such communities children learn to speak a language at home and in a community where that language is dominant, as is illustrated, for example, in the research of Koch et al. (2009) in a rural Eastern Cape school and Mashiya (2011) in rural KwaZulu-Natal schools. In such communities the school is, still, culturally and linguistically, a communal public space, where the identity of young children can easily be said to be formed by 'the village' that 'brings up the child'. It makes good sense that, in such places, children learn best in schools that do not opt for what is known as the 'early-exit' (Heugh, 2006) model of home language, or mother tongue instruction. According to this model, the most prevalent one in South Africa, schools switch to English by Grade 4. We assume that this switch is gradual in most instances. Researchers, such as Heugh (2006; 2008), argue, drawing from seminal studies conducted elsewhere in the world, that the 'late-exit' model, according to which children are gradually instructed in the end-language (English), but only fully so by Grade 6 to 9, promises the establishment of 'additive bilingualism' in the children's linguistic repertoire. This, in turn, is argued to become a sturdy cognitive tool for school learning in the transfer of cognitive academic language from one language to the other (Koch et al., 2009). Dampier (2012) argues, however, that the notion of 'additive bilingualism' is not a guarantee for linguistic equity.

Because of the rising currency of English as social capital, and despite the cries for more prominence for African languages in the public domain, it is not surprising that even rural schools introduce English as the language of learning and teaching (LoLT) much earlier than Grade 4. Mashiya (2011) found that teachers 'smuggled' English into their pedagogy in the foundation phase, because they regarded it as a passport to a better life for the children. She studied the use of language in rural KwaZulu-Natal schools and found that teachers saw themselves as facilitators of a better future for foundation phase learners by teaching them partly in English, despite what the policy, along with much research, recommends for the first, formative years of school. In this single investigation of 20 teachers the inherent tension regarding the language for learning is obvious, despite the homogeneity of culture and language in rural KwaZuluNatal. Strange as the logic may seem from the perspective of policy makers and academics, there is a strong groundswell of this cultural practice in schools, a practice 
that is by nature 'bottom-up'. Intuitively, teachers seem to want to ease the children's rite of passage into academic learning by giving English more prominence.

Our concern, however, is not with schools in linguistically (near) homogenous communities, such as rural KwaZulu-Natal, or the rural Eastern Cape, where the two mentioned studies were conducted, but with the children in schools in urban areas where there is a larger degree of linguistic diversity, such as in the industrial heartland of the country in the greater Johannesburg metropolitan area. Here growing children are exposed, and subject to, the various languages that are used in their suburbs and towns, some of which are, moreover, not indigenous to South Africa, with young children becoming venerable 'polyglots' (Makalela, 2009). The children who enter school in these areas are mostly exposed to, at least, three languages in their pre-school years. Godsell (2011) argues that the notion of 'mother tongue' is not easily defined in such areas. The children attending the English medium 'private' school (School A), that we studied, use up to eight different languages in their home environment. In the other, public school (School B), only Sesotho and IsiZulu speaking children are admitted.

School A provides for two pre-school years, as well as a Grade $\mathrm{R}$ year, in which to learn English before Grade 1, when the children are fully immersed in English as the medium of instruction. In School B there is a Grade R class, where English is already taught directly as the first additional language, by way of translation, in a bid to decrease intrasentential, random code-switching (Henning, forthcoming). In these two very different schools the problems are mostly the same, but they are approached in different ways. School A opts for immersion into English, with almost no attention being paid to the children's various home languages. There are just too many different 'mother tongues' for these to feature in the curriculum. In fact, these (mostly African) children learn Afrikaans as the first additional language. In School B the children learn their home language as the primary language, and in the foundation phase it is used for much of the pedagogy, with the exception of the teaching of numeracy, which is now taught partly in English', while isizulu and Sesotho are used in explanation and feedback, and also in back translations. The Grade 1 teachers translate and discuss concepts and processes in numeracy teaching into isizulu and Sesotho, while trying to avoid intrasentential code-switching. They, and the children, translate forward and backward (Henning, forthcoming), in the process trying to cement concepts in different lexis and syntax in both English and the mother tongue. The option to use English for numeracy teaching was the choice of the teachers when they realised, mid-way through the first cohort of Grade $R$ in this new school, that few children and teachers use the vernacular when talking about concepts, object names, and actions in numeracy and mathematics generally. The vernacular terminology seemed stranger than those in English for the young learners. The example given by these teachers and others with whom we have worked is the word for 'nine' in isizulu, which is isishiyagalolunye. This is also what Mashiya (2011) found in her study of the use of English in rural schools. The teachers and the principal in School B admitted 
that they had to think carefully to, for example, use counting words that they had long forgotten in their first languages of Sesotho or isizulu.

In this article, we examine the data from a study of the use of oral interactional English by 144 first graders; 71 in School A and 73 in School B, using a custom-designed instrument that assessed their listening and speaking competence, and thus also their phonological alertness and awareness. The instrument is also used in a longitudinal panel inquiry in School B over four years, capturing the children's growth in receptive and expressive oral English competence along with other measures that capture their cognitive development, their numeracy and mathematical competence, and their development in isizulu or Sesotho, as well as their literacy in two languages. For this article we report on the results of the first assessment of spoken English in this programme, and compare the children's competence in English with that of urban children who live in a similar community, but who go to the all-English private school (School A). What we wanted to find out in this part of the inquiry was only how the two groups of children compared on the same English spoken language competence test in Grade 1, when they are on the verge of their academic school career, after having settled into classroom routine and the school 'rituals'.

\section{On the threshold of school culture and the language of learning: A double liminality}

In our study of the children's English language competence we argue on three theories (cf. Figure 1). Firstly, we borrow the concept of 'liminality' from the field of anthropology. Originally this term was used to explain the transition phases between two periods in the rite of passage of children and youth, as studied by anthropologists, such as Van Gennep (1960) and Turner (1969). The application of the term has since spread widely and is now used to refer to any time period when a person is 'on the threshold' of a new phase of social development, such as the learning of a new language, or a new cultural practice (Iannacci, 2008). Liminality in Grade 1 can be seen as a cultural 'turning point' (Vygotsky, 1978) in the children's rite of passage towards becoming 'a learner in a school', or a 'pupil in a classroom', a position which changes their status in society. On this theory we view young children entering formal education as being liminal for a period of time, and would assume that this lasts no longer than a few months. They are on a threshold and they are, to use Turner's (1969) phrase, 'betwixt and between' informal home- and street-life, or pre-school and daycare centres, and formal schooling contexts. Upon entering formal education, they also have to learn a new language (i.e. English as the first additional language) along with what is a new culture. One can argue that there is now a double liminality; not only do they have to adapt to the new lifestyle with its specific cultural practices, but they also have to start learning the language that will, eventually, be the main medium of teaching and learning, in addition to getting acquainted with the specific form of their mother tongue, as used in the context of a school. For some the switch to 
instruction through medium of English will be as early as in Grade 4, in the 'early-exit' (Heugh, 2006) model of bilingual and dual-language education.

There is a real conundrum here for researchers, practitioners, and policy makers. Koch et al. (2009: 95) argue:

There is a large body of research (in Africa - for example, Bamgbose, 2000; McDonald, 1990; and amongst other linguistic minorities [sic] internationally (Ramirez et al., 1991; Thomas \& Collier, 2002) which shows that replacement of the mother tongue by a second or additional language by the start of schooling, or early transition to a second language as LoLT are not consonant with academic success, except where the mother tongue has high prestige or vitality in the so-called immersion programmes.

These authors continue in a comprehensive review of the literature by saying that children's mother tongue should ideally be established very firmly in a school context, taking around six years in a late-exit model of bilingual education, to ground them sufficiently and to prepare them to switch to their first additional language, English, which has been studied at school for a number of years as well, as the medium of instruction. Ideally speaking, we do not disagree. Pragmatically speaking, we have to disagree, although we consider both advantages and disadvantages in the three main options of 1) late-exit, 2) early-exit and 3) full immersion, the latter with the mother tongue as an object of study for as long as possible, and ensuring that it maintains 'high prestige' and 'vitality' as Koch et al. (ibid) suggest.

There are valid arguments, theoretically, for different standpoints: If the children are immersed into English too soon they stand to lose the known benefits of the 'lateexit' model. For literacy education, especially (Snow, 2010; Snow, Griffin \& Burns, 2005), they need refined phonological awareness of the language that will be the platform for their initial literacy, alphabetical skills (grasped and mastered) vocabulary (knowledge of the world), and syntax of the target language that they must learn to read. On the other hand, if they start learning through the medium of English later rather than sooner, they will not have sufficient English to carry them conceptually through the first murky waters of new concept learning. Reading comprehension and learning, generally, will be influenced negatively. Whichever way a school language policy may direct the learners they will have gains and losses. The research in South African does not as yet have longitudinal data to echo what bilingual education research in the USA, such Thomson and Collier (2002), has found after decades of large-scale research. We are not convinced, either, that these findings can be applied to all South African contexts, as most of the research in that vast literature concerns Spanish and English, or French and English, in the case of Canadian research - languages from the Indo-European group that share many similarities in syntax and morphology as well as lexis with English, with many cognates. This is not the case with indigenous South African languages.

In our study of the two groups, we viewed the data as indications of how the children are specifically using informal English as part of their 'rite of passage' into the language they will need for the bulk of their formal education, whether their schools follow the 'early-', or 'late-exit', or the 'immersion' policy. We, thus, examine a second 
form of liminality, the 'between languages' phenomenon of linguistic strangeness. However, the complexity of this second liminality is compounded, in all three models, by the fact that not only do the children need to learn another language in which to communicate, they also need to learn a specific form, or a set of discursive practices of this language that functions specifically in pedagogic contexts. They have to learn a 'school and subject language' with its expository and abstract textual characteristics. They have to learn the ways of decontextualised language. While being 'betwixt and between' their home language and English, they need to be enculturated into this specific form of language, known in the literature as "cognitive, academic language" (Cummins, 1979), which is probably the Achilles heel of bilingual and dual language education (Lems, Miller \& Soro, 2009) in the early grades. This is the language that will have to (eventually) communicate/capture abstract concepts (Setati et al., 2002).

The profile of a 'liminal' Grade 1 child in an urban South African school becomes more complex when one thinks of such a child's future trajectory through the next 11 years of school. The double liminality of the early grades is exacerbated by the fact that cognitive academic language itself may have to be learned in the bilingual mode, first, in the primary language of a classroom, and then later in English for seamless learning across the curriculum. Cummins (1979), who first theorised the distinction between the language of basic interpersonal communication skills (BICS) and cognitive academic language proficiency (CALP), recently emphasised the complexity of CALP as he continues to develop the theory. Lems, Miller and Soro (2009: 41) explain:

(Cummins) revised his ideas related to BICS and CALP (Cummins, 2003; 2008). And this included a third domain of discrete language skills that include phonology, literacy, and grammatical knowledge. These skills can be learned in conjunction with BICS and CALP, but they require teachers to use explicit instruction in which teachers demonstrate, or explain to students exactly how certain language features work.

These authors also say that CALP does not transfer directly from one language to another, something that seems to be assumed by many, as if it is a general, nonlinguistic tool that only manifests via language. Clearly authors are guided by their position on language and cognition ( $c f$. the edited volume of Bowerman \& Levinson, 2001). It takes a long time to develop CALP in any language and this is acknowledged by researchers who advocate the 'late-exit' option as strongly as Heugh (2006) does. Moreover, learners get accustomed to the register of academic language in the everyday details, the 'nitty-gritty' of language processing in a specific language, through which they then learn to use higher order skills that are communicated in specific registers. The details are learned through 'explicit instruction' (ibid). And the registers together form a discursive genre and are learned in pedagogical interactions so as to be used, as Vygotsky (1978) would describe it, as 'higher psychological tools'. These skills are not learned like BICS tools, for example, on the playground or in the community. Teachers teach them explicitly and they teach them within a target language in a specific subject. From this perspective the children in School A can be argued to have a better chance of acquiring the amount of (English) CALP they will need in the higher grades in primary school and later in high school sooner, because 
teachers infuse this type of language use into their pedagogy all the time. On this view one can also argue that the children in School A, thus, have some advantage, because they build cognitive academic language structures, in a 'nitty-gritty' way over time in the formative years of primary school. On the other hand, children who encounter it for the first time in English in Grade 4 or later then enter another liminal period; hovering there until they are proficient in the cognitive academic language of the various learning areas, in English. And we believe that each period of hovering 'betwixt and between' (Turner, 1969) delays learning, because it takes long to establish a firm grounding in CALP. Intuitively, the teachers at School B knew this, because they decided to teach mathematics and numeracy in English in Grade 1, to "make the learners feel more sure of what we say" (Teacher in School B). Cummins' (1979) theory also says that it takes many years to achieve CALP in a second language. In the current policy and practice context this would mean that most learners in South Africa will spend much of their primary school years learning the language of learning. Anthropologically speaking such learners will be in linguistic and, arguably, also in some conceptual limbo during this time.

Our view is that not enough linguistic, anthropological examination of young children as participants in school culture is conducted, and that a 'rite of passage' view of their beginning school years may add to our understanding of the psychological, and the social issues involved in learning during the foundation phase.

\section{Learning to use language as 'sign' in conceptual development}

Developing an (educational) anthropological view of young children's entry into school, would be incomplete without invoking a view on learning language and on learning to use it as a tool for the development of what Lev Vygotsky has termed, 'higher psychological processes', which are achieved by way of semiotic mediation (Vygotsky, 1978: 45). He distinguishes these processes from 'lower' or 'elementary' processes, which are innate and which develop naturally. We go directly to his discussion of one of his research findings in the 1930s:

We have found that sign operations appear as a result of a complex and prolonged process subject to all the basic laws of psychological evolution. This means that the sign-using activity in children is neither simply invented, nor passed down by adults; rather it arises from something that is originally not a sign operation and becomes one only after a series of qualitative transformations (ibid: 47 ).

Learning to use a language is closely connected with 'qualitative transformations' in cognitive development and specifically, we would add, with conceptual development. From this viewpoint, learning to use language means not only learning to communicate socially, but also learning to be involved in active and on-going interactions with those who use the sign (language), so that, during the interactions, a 'series of qualitative transformations' can occur because of the role that the sign plays in making these changes. With the aid of language and 'inner speech' (thinking) they are not only formed with language, but are also expressed in language. Although many concepts 
and naïve theories are formed by young children before they are able to express their knowing in language (in oral speech and in gestures), the rate at which these are formed increases incrementally with the use of language (Gopnik \& Nazzi, 2003; Gopnik, 2001; Bowerman \& Levinson, 2001). Briefly stated, thoughts and language meet bi-directionally; higher psychological processes and linguistic signs meet each other both in 1) the internalisation between the 'two planes' (the inter- and intrapsychological planes of which Vygotsky speaks often in his work), and 2) in the expression of thoughts in language, thus using the 'sign' both socioculturally and psychologically (Vygotsky, 1978; 1986; Kozulin, 1990). Thoughts and language are intertwined in both thinking and speaking/writing. On this view, one would argue that language is a scaffold for thought and that thought is, reciprocally, a scaffold for language, and that this holds true incrementally as children learn more language and become increasingly literate as well. The development of CALP follows this process.

On the surface, this notion would seem to militate against the use of contemporary cognitive developmental psychologists' views to explore the relationship between language and learning, because many of these scholars are perceived as 'innatists', a rude term if ever there was one in the sociocultural (neo-Vygotskian) education community. Nonetheless, we fruitfully use the ideas of Susan Carey (1985 2009) and Alison Gopnik (2001, 2003), for instance. For us there is not a scholarly 'divide' between 'innatists' and 'culturalists' or 'interactionists'. We do not ascribe to such a divide that deprives a fuller view of learning and language, because from the psycholinguistic, cognitive developmental literature (such as Bowerman \& Levinson's edited volume, 2001; Evans \& Levinson, 2009) it is evident that cognitive development and linguistic development need to be studied in tandem and that Vygotsky, whose work spawned many interactionist theories, recognised this. We also think that there is an 'interactionist' leaning in the work of cognitive developmentalists, such as Carey and Gopnik, which is often not examined by radical socioculturalists, such as Rogoff (1990). Moreover, we think it is important to produce an astute account of the interlinking notions discernable in theories on learning and language, which is why we invoke the work of developmental cognitive psychologists along with classical Vygotskian theory (1978; 1986).

We specifically give attention to the notion of the 'theory' theory of cognitive development (Gopnik \& Meltzoff, 1997; Gopnik, 2001), which proposes that very young children learn to engage in their world by hypothesising and testing their observations in their actions, including their use of signs, as their biological development increases and as they then can observe more and more of their world as they become more mobile. They construct naïve theories about their world, and during interactions with other humans learn to name components of these theories, not only with reference to objects, but also actions and even emotions, and other 'things of the mind' (Gopnik \& Meltzoff, 1997). They 'bootstrap' the different stages of their theory building (Carey, 1985 ; 2009) with one concept leading to another until a theory works well enough to be tested and practiced. From around 15-18 months this process accelerates because with more signs available, more concepts can be organised with the help of language 
as toddlers take on the world and the signs around them. Utilising their basic and innate brain architecture, children start developing their minds and start to control their lives and to direct the further unfolding of their very brain- and mind architecture. And all of this happens in continuous interaction with the (cultural/signing) world around them. It is an on-going dialectical process, captured in the work of Vygotsky, who added a historical, material tone to his view of this learning process (Vygotsky, 1978: 73):

Our concept of development implies a rejection of the frequently held view that cognitive development results from the gradual accumulation of separate changes. We believe that child development is a complex, dialectical process, characterised by periodicity, unevenness in the development of different functions, metamorphosis, or qualitative transformation of one form into another, intertwining of external and internal factors, and adaptive processes which overcome impediments that the child encounters.

Elsewhere Vygotsky uses the term 'interlacement' (John-Steiner \& Souberman, 1978) to emphasise that higher mental processes 'interlace' with what has been given to humans biologically. He posits that, in the tradition of Freidrich Engels, from whom he learned much regarding human work and tool-use in development, it is the tool, and especially also the signing tool (such as language), that plays a significant role in the development of these higher psychological functions (Cole \& Scribner, 1978: 1-15). What we find in this part of Vygotsky's work is that semiotically mediated action (learning through the use of signs and other tools) contributes substantially to the development of higher mental functions.

Thus, we argue that in the already challenging liminal phase of children's school entry there is an added liminality; it is the liminality of language for CALP purposes. Children have to learn to use language in a very specific way as a higher functioning tool and as scaffold for their conceptual development; they learn a new discourse with its own discursive practices, of which the very new discourse of numeracy/mathematics is one example. They test new theories of their world. The 'threshold' of the liminal period may extend too far into their primary school journey when they have to learn new sign-use when, rather, they could be learning concepts in quick succession with already existing signs. What we are saying is that by the time children reach Grade 4 signs should be scaffolding this learning incrementally as they represent the abstract world in science, in mathematics and in learning about the world. Advocates of the 'late-exit' model may not have it right for current urban South African conditions. If the signs and signing systems of primary school children are not secured in one CALP as early as possible, they may remain in limbo, 'betwixt and between' two underdeveloped (bilingual) CALPs, harvesting the worst of two educational worlds. 


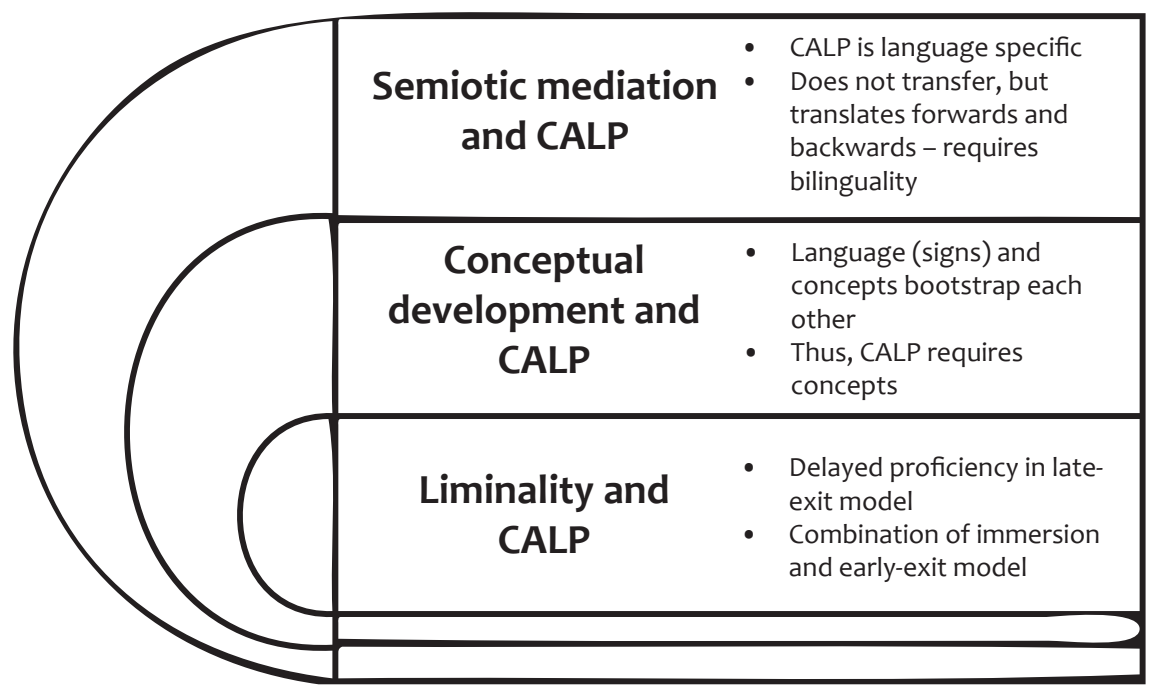

Figure 1: Three intersecting theories to examine language (CALP) and learning in multilingual contexts.

From this discussion of a double liminality our argument emerges: We make the claim that urban children in multilingual contexts in South Africa may, ultimately, be advantaged if they can learn English in their pre-school years as they do in School A. They already learn much more of the additional language than is advocated by Koch et al. (2009) for rural schools in the late-exit model. There is a caveat, though, in this argument: by the same token it is essential that they study their own home language as a first additional language so that it can 'interlace' with English CALP and retain its vitality. We believe that this 'interlacing', which should not be confused with codeswitching, or with direct CALP transfer, is one of the assets of bilingual education and dual language education models. Bilingual people generally have a wider access to knowledge if both languages are well developed. Another caveat is that although our reasoning is definitely pragmatic, we do not doubt that language is part of identity and we do not wish for the diminishment of the tapestry of South African languages, or of the right to 'mother tongue instruction' against the wishes of such fervent advocates for it as Skutnabb-Kangas (2009) for instance. We forward this view because it is educationally fair and socially just to educate children optimally and to prepare them for learning as comprehensively as possible right at the outset of their school career. The jury is still out on the benefits of late-exit models of mother tongue instruction in the research community in South Africa. But the judgment on South African children, not only in the often mentioned international surveys, but increasingly in research here at home as well ${ }^{4}$, is that our young children and youth are not learning enough to sustain them or their country. In ex-model C schools they seem to do better (Godsell, 
2011), perhaps because of many variables, one of which is that in those schools they develop English CALP early.

\title{
The inquiry: Capturing language comprehension and expression in Grade 1
}

The test items on the instrument were designed to get a glimpse of the children's basic interpersonal communication skills, ranging from vocabulary (naming words) and a little more complex morpho-syntactical skills. The test included discussion of photos and oral communication with the interviewer, who spoke only in English. The design logic of the tool was that children would be able to participate individually in a test period of about 20 minutes, in which we would get a sense of their use of English at an interpersonal, informal level (BICS, in Cummins's theory). We aimed at finding some indication of phonological sensitivity, semantics, and grammar and syntax, by assessing their listening and speaking competence. We also wished to judge some organising ability of the English that they know already, especially in the items that required some elaboration and coherence of expression. Because the test will be repeated for four years, their growth can eventually be measured and compared to the results in the standardised mathematics and the cognitive ability tests and other tests that are also administered over four years. The test would, for now, also capture their pragmatic knowledge of English in the following categories in items that relate to different parts of their lives:

\author{
Family and home \\ Images and objects in context \\ Decontextualised images and objects \\ Popular culture and icons \\ Oral instructions \\ Greeting
}

Because the test is used in conjunction with other tests in the mentioned panel inquiry of four years in School B, the levels of complexity of the responses were coded on a scale from 0-6, so that individual children's development may be gauged over time in all of these various tests of numeracy and mathematics knowledge, general cognitive ability development, and competence in isizulu or Sesotho in typical panel design logic.

The rating scale is aimed at measuring the level of spoken language (BICS) competence in accordance with the following seven categories:

$0=$ No reaction, answer given that did not relate to the question or the student spoke in his/her mother tongue.

1 = Names one object or action. No clauses. One word answers.

$2=$ Names two objects or actions. No clauses. One word answers.

$3=$ Names two or more objects or actions and constructs a simple clause structure (subject, verb). 
$4=$ Names more than two objects or actions and constructs a full sentence (subject, verb and object).

$5=$ A coherent utterance with more than one sentence and use of pronouns.

$6=$ Flowing coherent utterance with more than three sentences and with use of pronouns, adjectives and adverbs, utilising sub-clauses.

In May and June 2011 one researcher administered the tests in both schools. In School A 71 children from a total of 240 were selected, while all 73 children in Grade 1 at School B participated. The test administrator conducted the interview with each child individually, recording their responses to the various items during the sessions and immediately afterwards.

The scores were entered into the PASW Statistics 18 programme and were analysed for reliability and normality, while means for the different schools were compared and analysed for significant differences.

\section{The results}

As expected, the children from School A, where English is introduced at least two years before the children enter Grade R, performed significantly better than students from School B, where instruction is conducted in the mother tongue of the respective classes, i.e. isiZulu and Sesotho. The mean scores for pupils from School A is 3.22 (Figure 2) on the rating continuum, while the results for School B is 1.78 (Figure 3). The children in School A were able to name two or more objects and actions using the subject, verb structure frequently and with ease. 
Histogram

- Normal

for Institution = School A

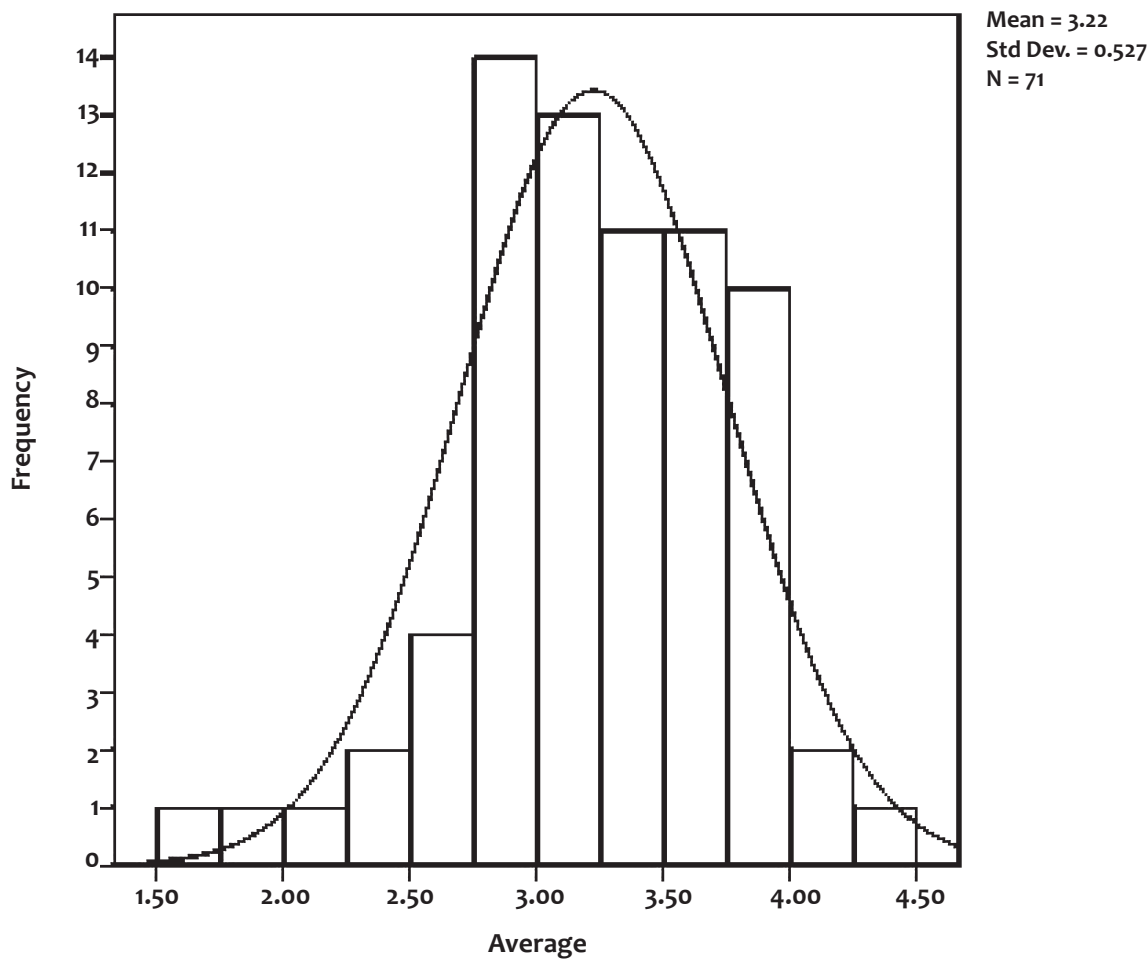

Figure 2: Average scores for students from School A.

By comparison, more students from School A were, in general, able to answer in complete sentences, while fewer students from School B were able to do so. In fact, the ability of children in this school, to answer in complete sentences appears to be isolated and incongruous, since the majority are, at best, only able to name a number of objects. Few go so far as to supply answers that employ the subject, verb structure, as is revealed in the following illustration: 
Histogram

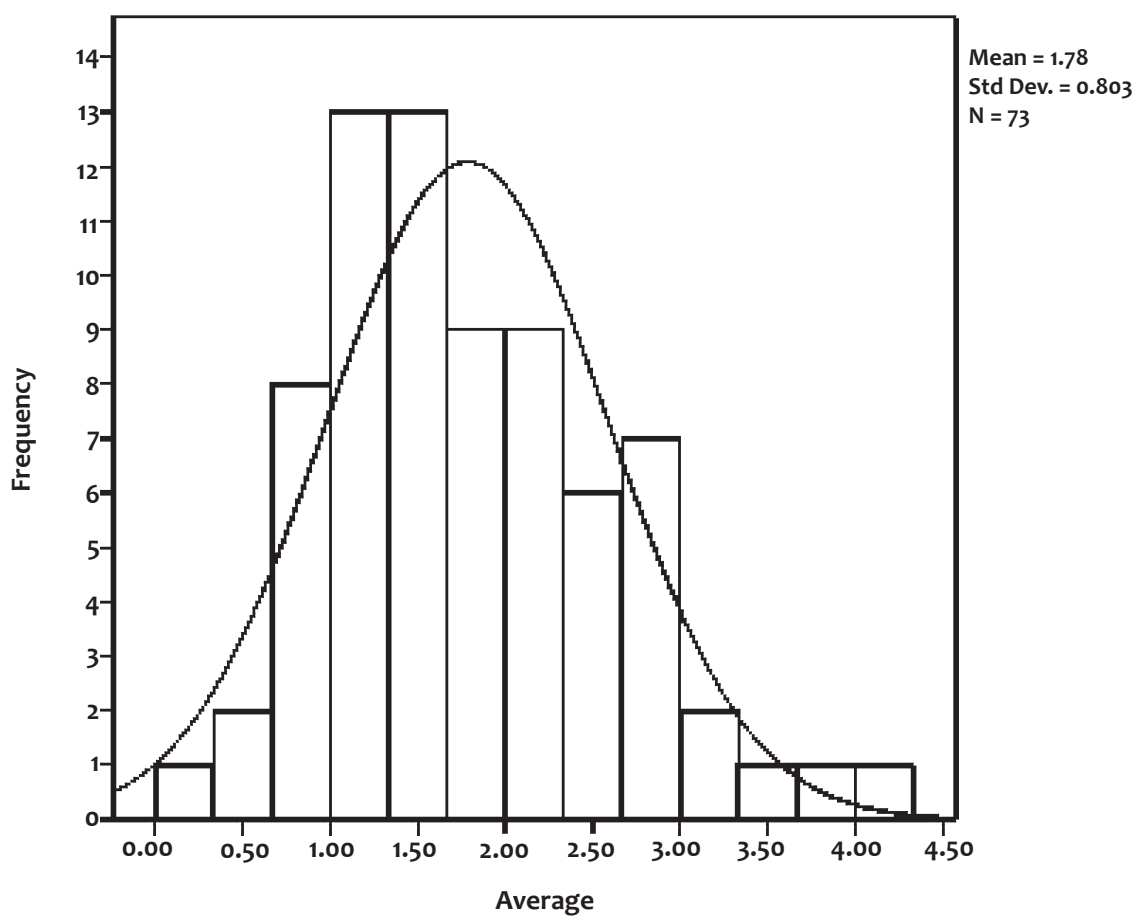

Figure 3: Average scores for students from School B.

The majority of children in School B provided answers that fall within the categories 0 , 1 and 2 on the rating continuum, which suggests that for the most part students were able to name objects using one word, nominals only and no verbals.

\section{Discussion: Early immersion into English: Advantage or disadvantage?}

In our analysis we were again confronted with the literature, both in South Africa and elsewhere, especially in the USA, that claims advantage for home language (Snow, 2010; Alexander, 2009; Heugh, 2008, 2006; Koch et al., 2009) in early schooling. There are many publications on this topic and it is becoming a burning issue in manuscripts submitted to South African journals, such as the South African Journal of Childhood Education and the South African Journal of Education. The argument remains the same: in the long run it is better for children to be educated in their home language and to learn to read and write and become numerate in this language, even if they have to transfer to another language eventually. Leading figures in South African public discussion of language in schools consistently argue for various positions on the 
'mother tongue side' of the debate, focusing on identity, better learning as well as upward mobility in one utterance. Our position is that this position is impossible and that bilingual education research in English and Spanish, which is what most debaters refer to, cannot be transferred wholly to South African conditions and history.

New research is beginning to question this view. Firstly, in accordance with Cummins's theory and much subsequent research, there is agreement that the time for CALP to develop is substantial, varying between five and eight years (Koch et al., 2009) and, secondly, CALP does not transfer from the first language to the second language (Lems et al., 2009), because the logic of CALP is syntactical and also lodged in some morphology. In fact, CALP in the second language relies on knowledge of the second language itself; and CALP requires 'nitty-gritty' features that are learned over time in any one language (Lems et al., 2009). If one accepts the view that CALP is a major 'higher psychological tool', then one has to conclude that CALP (in English) needs to be developed as soon as possible for children who are going to learn through the medium of English if such education is available. The challenging question is, of course, how that may be done. There is much irrationality in language policy in education (Heugh, 2006, 2008; Makalela, 2005; 2009) and in South Africa substantial, large scale, longitudinal research is needed to make feasible and fair suggestions. To get empirical answers to the burning issues of language and instruction will, however, require much time and research funding. Even small-scale research, such as the exemplary work of Koch et al. (2009), is costly and it requires time. In fact the school where they based their intervention is slowly coming apart at the seams and their theorising about bilingual education and the role of isiXhosa in learning may have to be taken elsewhere for empirical extension. South African children cannot be left in a maze of liminality and random code-switching until, perhaps, somewhere in the future, we will know if the research conducted elsewhere can really be applied to our context.

The results of this inquiry will be further interpreted when the (home language) BICS of children in School B has been analysed - to see what their competence in their first language is and how that compares to the competence in English of the children in School A. Preliminary results show that the children mix two or more African languages with English and that they speak a child version of isicamtho, often not knowing how to respond to the formal language. For now, however, these results signal a warning. The chances that teachers will be able to infuse CALP in English sufficiently before Grade 4 are weak. A middle road will have to be sought through translation and unambiguous 'switching' of language code in classrooms.

The results of studies, such as those conducted by Mashiya, (2011), and the damning evidence of international surveys of competence in literacy and mathematics, in which South African pupils participated, signal the same warning. Although most analysts look for the problem elsewhere, such as in lack of school resources, teacher quality, school culture, school management, home resources, poverty, illness, the role of the unions, and many more, the issue of the possible negative effects of 'mother tongue instruction' is not raised with any conviction, although the issue of language is almost 
always alluded to. No one wants to say outright that the language policies may be one of the sources of the lack of advancement of the majority of young children. For some it may be regarded as linguistic suicide, or 'genocide', as Skutnabb-Kangas (2009) puts it, on par with the dying out of natural species. ${ }^{5}$

We argue that it may well be that mother-tongue instruction can be one of the roots of our educational problems, not because the African languages of this country cannot capture concepts, but because their use in classrooms seems to be inconsistent at a time when young children, on the threshold of formal education, desperately need linguistic consistency. Researchers who are firm advocates of multilingual education (cf. the edited volume by Skutnabb-Kangas \& Heugh, 2010) need to investigate the schools in metropolitan Johannesburg to witness how children and teachers struggle in the language maze; especially, since multilingual textbooks that present the cognitive language children need to develop advanced literacy, are not the norm beyond Grade 4 (Mahlalela-Thusi \& Heugh, 2010). In fact, publishers compete to sell the most English textbooks, an example of which is the 10 current English textbooks for history education. ${ }^{6}$

Early school is a time when young learners need to be able to trust the signs that they encounter for the long term - signs that help them to build concepts of a 'higher psychological' order (Vygotsky, 1978), and with which they can build sturdy CALP frameworks. We are concerned about the possible dangers of an extended linguistic liminality. The 73 children in School B are already somewhat bilingual. Their 'conversational' English is, however, limited to single words or broken clauses. No one can predict if, or when, they will be on par with the children in School A, and whether they will surpass them in performance eventually in the use of (English) CALP in their learning beyond the primary school. What we can say, based on the findings, is that the children in School B carry a heavier load in their rite of passage.

\section{Conclusion: Are urban children getting their fair share of education?}

In both the schools that we investigated, but especially in School A, there is a joyful use of different languages, creoles and dialects when the children are not engaged in formal class work. In fact, on the grounds of School A there is a venerable 'Tower of Babel' noise during break times. Children from Zimbabwe, Nigeria, the DRC and Ghana can be heard playing and singing along with children from different parts of South Africa. When they get to the classroom door, they enter that space of school culture where they change their code of conduct and their linguistic code and the foreground their functional language identity. When the tests were conducted with them, they were comfortable and entered the 'English' space of their lives, using its signs as artefacts and tools quite confidently. The children in School B, when they took the tests, entered an unfamiliar domain, where the security net of their language was not available. Although they understood some of the questions, the response did not come naturally to them, because they had not learned this linguistic code and this code of conduct. 
If we juxtapose the two schools, it can be said, when looking at the surface information at this moment in time, that the children of School A have an advantage in terms of developing a sturdy CALP, which will scaffold their learning from now on, and which will not change to another code. The children in School B will have learned CALP in a bilingual, dual-language way, because during all of the school day they use their home language, but when they learn numeracy and mathematics, they switch to English. We wonder how secure they feel, and whether their liminality will persist. We also wonder what the implications are for the building of concepts, given the new world they will have to enter in Grade 4, and given the bootstrapping role of language signs and conceptual development (Gopnik, 2001 Bowerman \& Levinson, 2001).

In order to take a cognitive developmental and psycholinguistic developmental look at children's learning in the first year of school, it is not unwarranted to invoke an anthropological perspective as we have done in this article. The advantage of such a perspective, with regard to language and pedagogy, is that it takes one out of the discourse of policy and the politics of language and identity. It simply sees the school as an important cultural place, where new entrants arrive in a liminal state, and where, perhaps, this entry into 'schoolhood' should be made somewhat easier for the novice learners, so that they can leave the sense of 'betwixt and between' behind them as soon as possible, and get on with what their real cultural practice in school is. They need to learn to think and do their utmost to unfold their potential in a society that needs each of them to build a future. If they are kept in linguistic limbo for too long, they miss a period of their rite of passage that they can never repeat. In social cultures one has to grow up and become an adult to be integrated in society. Cultures, dynamic as they are, can be ruthless in this regard: you always have to move on to the next phase in your passage (traveling), or move out, or into a sub-culture, such as unemployed youth do. 'Schoolhood' is an important stage in cultures everywhere. Young people who do not go through this stage successfully are relegated to the margins of society as 'liminars' (Turner, 1982), without employment, without future, and without voice.

As conclusion to their article Koch et al. (2009: 107) express the following wish with regard to the 'late-exit' model of additive bilingualism in education:

As the additive model is rolled out in more schools there is a strong hope that the inequities resulting from South Africa's colonial and political history will be eroded, as learners are given the opportunity to learn to high levels through their mother tongue and at the same time achieve high levels in English.

From the perspective of our inquiry this hope is not likely to be realised in most of the urban, public schools that we know in areas such as Soweto.

\section{Endnotes}

1. Turner (1969) uses this term to describe the stage between two cultural phases in a rite of passage.

2. Schools such as School A are subsidised by the provincial education department and have something in common with the 'charter schools' in the USA as well as the 'private education 
for the poor' movement started by James Tooley and explained by Hofmeyr \& McKay (2010) in the South African context.

3. The annual national assessment in numeracy in Grade 2 is administered in English, for example, while the literacy tests is conducted in the mother tongue.

4. The disturbing Annual National Assessment results have just been made available. In it the downward trend in foundation phase learning is evident.

5. This same author also has argued that functional language identity is to be distinguished from personal language identity.

6. Morgan (2010) found that only one of them embraces the spirit of the curriculum.

\section{References}

Alexander, N. (2009). Mother tongue bilingual teaching is the key. A paper presented at the colloquium on mother tongue teaching in the early years. University of KwaZulu-Natal. 22 May.

Alexander, N. (2002). English unassailable but unattainable. The dilemma of language policy in education in South Africa. PRAESA Occasional Paper No 3. Cape Town: PRAESA/University of Cape Town.

Bowerman, M. \& Levinson, S. C. (Eds.) 2001. Language acquisition and conceptual development. New York: Cambridge University Press.

Burkett, B. \& Landon, J. (2004). Introducing an additive bilingual model of education in a rural Xhosa-speaking area in Eastern Cape Province, South Africa: Preparing the ground. Paper delivered at the annual conference of the American Association of Applied Linguistics. Portland, Oregon, 1-4 May.

Carey, S. (2009). The origin of concepts. Oxford: Oxford University Press.

Carey, S. (1985). Conceptual change in childhood. Cambridge, MA: Bradford/MIT Press.

Cole, M. \& Scribner, S. (Eds.) (1978). Introduction to L. Vygotsky, Mind in society. Cambridge: MIT Press, pp.1-14.

Cummins, J. (1979). Cognitive academic language proficiency: linguistic interdependence, the optimal age question and some other matters. Working papers on bilingualism, 19: 197-205.

Evans, N. \& Levinson, S. C. (2009). The myth of language universals: Language diversity and its importance for cognitive science. Behavioral and Brain Sciences, 32(5): 429-492.

Gopnik, A. (2001). Theories, language, and culture: Whorf without wincing. In: M. Bowerman \& S. C. Levinson, (eds.), Language acquisition and conceptual development. New York: Cambridge University Press, pp. 45-69.

Gopnik, A. \& Meltzoff, A. N. (1997). Words, thoughts, and theories. Cambridge, MA: MIT Press.

Gopnik, A. \& Nazzi, T. (2003). Words, kinds and causal powers: A theory perspective on early naming and categorization. In: D. Rakison, \& L. Oakes (eds.), Early category and concept development: Making sense of the blooming, buzzing confusion. New York: Oxford University Press, pp. 303-329. 
Godsell, G. (In press). Moving forward school by school. In: M du Preez (ed.), None so daunting. Johannesburg: Penguin Books.

Henning. E. (forthcoming). Learning concepts, language, and literacy in 'code-switching' classrooms: The matter of linguistic instability. Perspectives in Education.

Heugh, K. (2008). Language Policy and Education in Southern Africa. In: S. May \& N. Hornberger (eds.), Volume 1: Language Policy and Political Issues in Education. Encyclopedia of Language and Education. Second Edition. New York: Springer Science + Business Media, LLC, pp. 355-367.

Heugh, K. (2006). Language education models in Africa: research design, decisionmaking, and outcomes. In: ADEA. Optimizing learning and education in Africa - the language factor: a stock-taking research on mother tongue and bilingual education in sub-Saharan Africa. Paris: Association for Development of Education in Africa. ADEA, pp. 59-84.

Hofmeyr, J. \& McKay, V. (2010). Private education for the poor. More, different and better. Focus, 56: 50-56

Iannacci, L. (2008). Beyond the pragmatic and the liminal: Culturally and linguistically diverse students code-switching in early-years classrooms. TESL Canada Journal, 25(2): 103-123.

John-Steiner, V. \& Souberman, E. (1978). Afterword, L. Vygotsky, Mind in society. Cambridge: MIT Press, pp. 121-134

Koch, E., Landon, J., Jackson, M.J. \& Foli, C. (2009). First brushstrokes. Initial comparative results on the additive bilingual education project. Southern African Linguistics and Applied Language Studies, 27(1): 93-111.

Kozulin, A. (1990). Vygotsky's psychology: A biography of ideas. Cambridge, MA: Harvard University Press.

Lems, K., Miller L. \& Soro, T. M. (2009). Teaching Reading to English Language Learners: Insights from Linguistics. New York: Guilford Publishers.

Mahlalela-Thusi, B. \& Heugh, K. (2010). Terminology and School Books in Southern African Languages. Aren't there any? In: B. Brock-Utne, Z. Desai, M. Qorro \& A. Pitman (eds), Language of Instruction in Tanzania and South Africa - Highlights from a Project. Rotterdam, Boston and Taipei: Sense Publishers, pp.113-133.

Makalela, L. (2009). Unpacking the language of instruction myth. Toward progressive languages in Africa In: B. Brock-Utne \& J. Brah, Paradigms for language policies in African Education, pp.170-194.

Makalela, L. (2005). We speak 11 tongues: Reconstructing multilingualism in South Africa. In: B. Brock-Utne \& R. Hopson (eds.), Language of instruction in postcolonial Africa: Issues and considerations. Cape Town: Mkuki na Nyota Publishers, pp. 147-174.

Mashiya, N. (2011). IsiZulu and English in KwaZulu-Natal rural schools: How teachers fear failure and opt for English. South African Journal of Childhood Education, 1(1): pp (to be added on 13 July). 
Morgan, K. E. (2010). Textbooks as mediators in the intellectual project of history education. Unpublished PhD thesis. University of Johannesburg.

Rogoff, B. (1990). Apprenticeship in thinking. Cognitive development in social context. New York: Oxford University Press.

Setati, M., Adler, G., Reed, Y. \& Bapoo, A. (2002). Incomplete journeys: Code-switching and other language practices in mathematics, science, and English language classrooms in South Africa. Language and Education, 16(2): 128-149.

Skutnabb-Kangas, T. (2009). The stakes: Linguistic diversity, linguistic human rights and mother tongue based multilingual education - or linguistic genocide, crimes against humanity and an even faster destruction of biodiversity and our planet. Keynote presentation at the Bamako International Forum on Multilingualism, Bamako, Mali, 19-21 January 2009.

Skutnabb-Kangas, T. \& Heugh, K. (2010). Introduction - Why this book? In: K. Heugh \& T. Skutnabb-Kangas (eds.), Multilingual education works: From the periphery to the centre, Delhi: Orient Blackswan, pp. 3-39.

Snow, C. (2010). Preparations for literacy: The early years. Public lecture in the Faculty of Education, University of Johannesburg. 18 August. [Online.] Available from: http://www.uj.ac.za/ujice.

Snow, C., Griffin, P. \& Burns, M. S. (2005). Knowledge to support the teaching of reading. Preparing teachers for a changing world. San Francisco: Jossey-Bass.

Thomas, W. P. \& Collier, W.P. (2002). A national study of school effectiveness for language minority students' long-term academic achievement. [Online.] Available from: http://crede.berkeley.edu/research/crede/research/llaa/1.1_es.html.

Turner, V. (1982). From ritual to theatre: The human seriousness of play. New York: PAJ Publications.

Turner, V. (1969). The forest of symbols: Aspects of Ndembu ritual. Ithaca, NY: Cornell University.

Van Gennep, A. (1909/1960). The rites of passage. Chicago: University of Chicago press.

Vygotsky, L. (1986). Thought and language (edited and revised by A. Kozulin). Cambridge, MA: MIT Press.

Vygotsky, L. (1934/1978). Mind in society. The development of higher psychological processes. (edited and translated by M. Cole, V. John-Steiner, S. Scribner \& E. Souberman), Cambridge, MA: Harvard University Press. 